\title{
CIUDADANÍA Y VIOLENCIA DE GÉNERO SOBRE LA MUJER TRABAJADORA: REFLEXIONES A LA LUZ DEL ORDENAMIENTO JURÍDICO ESPAÑOL Y BRASILEÑO
}

\section{Susana Rodríguez Escanciano}

Doctora en Derecho por la Universidad de León (España), Catedrática de Derecho del Trabajo de la Universidad de León - UNILEÓN (España).

Mirian Caldas

Doctora en Derecho por la Universidad de León (España), Profesora Colabora en la Universidade Estadual do Centro-Oeste do Paraná - UNICENTRO (Brasil).

\section{Resumen}

Ha pasado casi una década desde la IV Conferencia Mundial sobre la Mujer, celebrada en Beijing en 1995, donde se reconoció la violencia contra la mujer como un ataque a los derechos humanos de las féminas. Bajo tal perspectiva y siguiendo las recomendaciones de las instancias comunitarias y organismos internacionales, Estados, como España y Brasil, han incorporado en sus respectivos ordenamientos previsiones específicas -- Ley Orgánica 1/2004, de 28 de diciembre, de Medidas de Protección Integral contra la Violencia de Género (LPIVG), en Espańa; y Ley 11.340/2006 (Lei Maria da Penha), en Brasil --. Estas dos disposiciones tienen, entre sus objetivos fundamentales, atacar con firmeza tan deleznables comportamientos de violencia contra la mujer, articulando un conjunto de medidas tendentes a garantizar de forma global, plena y coherente la protección de las mujeres maltratadas, convirtiéndolas en titulares de un amplio abanico de derechos atinentes a la prevención, educación, asistencia social o represión penal y, por lo que aquí interesa, de una serie de prerrogativas laborales y de Seguridad Social, conformando, a la postre, una estrategia dotada de una doble finalidad: de un lado, facilitar el acceso al empleo de las mujeres víctimas de violencia de género y, de otro, conseguir el mantenimiento de sus puestos de trabajo. El estudio comparado de ambos ordenamientos puede servir para introducir mejoras técnicas que redunden en beneficio del colectivo protegido.

\section{Palabras clave}

Mujer; Violencia de género; Violencia doméstica y familiar; Relaciones laborales; Contrato de trabajo. 


\section{Abstract}

It has been nearly a decade since the Fourth World Conference on Women held in Beijing in 1995, where the violence against women was recognized as being an attack on women's human rights. Under such perspective and following the recommendations of the community institutions and international organizations, States such as Spain and Brazil have incorporated into their systems specific laws -- Organic Law 1/2004 of 28th December, on Integral Protection Measures against Gender Violence (LPIVG), in Spain and Law 11.340/2006 (Lei Maria da Penha), in Brazil --. These two provisions have as one of its fundamental objectives, firmly attack such despicable behaviors of violence against women, articulating a set of measures to ensure a whole, full and consistent protection of battered women, making them hold a wide range of rights pertaining to prevention, education, welfare or criminal repression, and down to what is relevant, a series of labor and social security prerogatives, confirming in the end, a dual purpose endowed strategy: on the one hand, facilitate the employment access for women victims of gender violence and, on the other, ensure the maintenance of their jobs. A comparative study of both legal systems may serve to introduce technical improvements that result in benefit of the protected group.

\section{Key words}

Women; Gender violence; Domestic and family violence; Labor relations; Labor contract.

\section{Introducción}

La igualdad efectiva entre mujeres y hombres como principio jurídico universal y como valor fundamental de la Unión Europea, no puede llevarse plenamente a la práctica en tanto se perpetúe el ejercicio de distintas formas de violencia sobre la mujer por el mero hecho de serlo. Es fácil entender cómo la magnitud de este fenómeno violento cuestiona día a día los derechos fundamentales de ciudadanía de muchas mujeres --derecho a la vida, a su integridad física y psíquica, a su dignidad y libertad--, los cuales constituyen pilares inviolables de la persona y estandartes insoslayables del orden democrático, circunstancias que obligan a los poderes públicos a adoptar respuestas técnico-jurídicas para hacer real su disfrute.

El Informe de la Organización de las Naciones Unidas (ONU) enuncia una serie de medidas que deben adoptar los Estados para prevenir y eliminar la violencia contra la mujer, imponiéndoles la obligación de condenar la violencia contra la mujer y de invocar "ninguna costumbre, tradición o consideración religiosa para eludir su obligación de eliminarla". Con claridad, establece que "la violencia contra la mujer es a la vez una 
violación de los derechos humanos de las mujeres y un obstáculo para el pleno disfrute" (ONU, 2006).

En este estudio se pretende hacer un estudio comparado entre dos ordenamientos distintos. Primeramente se verificará la protección de la mujer en España, a través del análisis de algunos puntos de Ley Orgánica 1/2004, de 28 de diciembre, de Medidas de Protección Integral contra la Violencia de Género (LPIVG), y los reflejos de esta Ley en el ámbito laboral; y en un segundo momento, se verificará la evolución de la protección a la mujer víctima de violencia en Brasil, tras la promulgación de la Ley 11.340/2006 (Lei Maria da Penha) y la garantía del mantenimiento del vínculo laboral como medida protectora de asistencia a la mujer víctima de violencia doméstica y familiar.

Desde un primer momento, cabe esclarecer que en el ordenamiento jurídico español suelen utilizarse dos conceptos jurídicos con significados diferentes, cuales son la "violencia de género" y la violencia doméstica". La primera refiere a la violencia ejercida por el hombre sobre la mujer por el hecho de ser mujer, ya se produzca bien en el ámbito público como en el privado. Por el contrario, violencia doméstica es la ejercida sobre cualquier miembro de la unidad familiar. La normativa española tiene en cuenta la senda que marcó la ONU con la Declaración sobre la eliminación de la violencia contra la mujer en la Resolución de la Asamblea General 48/104 de 20 de diciembre de 1993 y en la que definía "violencia contra la mujer", en su artículo 1, como "todo acto de violencia basado en la pertenencia al sexo femenino que tenga o pueda tener como resultado un daño o sufrimiento físico, sexual o psicológico para la mujer, así como las amenazas de tales actos, la coacción o la privación arbitraria de la libertad, tanto si se producen en la vida pública como en la vida privada", siempre que el agresor sea la pareja o expareja. Sin embargo, en el ordenamiento jurídico brasileño el artículo 1 de la Ley 11.340/2006 utiliza los términos mujer víctima de violencia doméstica y familiar (violência doméstica e familiar contra a mulher). Es más, según Maria Berenice Dias, la Ley "Maria da Penha" regoge una protección no sólo a la mujer (violencia de género), sino a la mujer en su propia unidad familiar, al tratar de la violencia doméstica (DIAS, 2012). Las autoras de esta ponencia realizan esta aclaración con fin de que los términos utilizados no conduzcan a error, por cuanto en el contenido de este trabajo principalmente utilizará a los términos violencia doméstica y familiar por ser la traducción literal de la Ley 11.340/2006, sin desconocer la precisión que se realiza en el Derecho español, a la luz de la Ley Orgánica 1/2004.

\section{La Preocupación de la Ley Española 1/2004 - LPIVG - por las Mujeres Trabajadoras Víctimas de Maltrato Machista}

Nadie puede poner en duda que la violencia ejercida sobre las mujeres por parte de quienes han mantenido o sostienen con ellas una relación afectiva es un problema real - hoy 
más vigente que nunca - necesitado de soluciones efectivas. Sólo por esta razón ya resulta indudable la oportunidad y el valor de la Ley Orgánica 1/2004, de 28 de diciembre, de Medidas de Protección Integral contra la Violencia de Género (LPIVG), cuyo objeto es el de "actuar contra la violencia que, como manifestación de la discriminación, la situación de desigualdad y las relaciones de poder de los hombres sobre las mujeres, se ejerce sobre éstas por parte de quienes sean o hayan sido sus cónyuges o de quienes estén o hayan estado ligados a ellas por relaciones similares de afectividad" (art. 1).

Un año después del décimo aniversario de esta disposición legal, la persistencia de las situaciones amparadas invitan a hacer balance sobre sus resultados reales, máxime teniendo en cuenta que España ha ratificado Convenio del Consejo de Europa sobre prevención y lucha contra la violencia contra la mujer y la violencia doméstica, hecho en Estambul el 11 de mayo de 2011. Al objeto de aquilatar los términos de la reflexión, procede dejar claro, desde el principio aun a riesgo de ser reiterativos, que no se protege cualquier menoscabo ejercido por los hombres contra las mujeres, sino únicamente aquél producido en el seno de una relación de pareja, actual o ya finalizada, entre un varón y una fémina, abarcando todos los delitos que impliquen "violencia física y psicológica, incluidas las agresiones a la libertad sexual, las amenazas, las coacciones o la privación arbitraria de libertad". A sensu contrario, para apreciar la existencia de un delito de violencia de género no basta lisa y llanamente con que la ofendida hubiese sido esposa, pareja o compañera del autor, sino que se hace necesaria la existencia de un plus, cual es que esa conducta de maltrato pueda calificarse como una manifestación de la discriminación, y las relaciones de poder y dominio de los hombres sobre las mujeres, lo cual concurre en todos los tipos de violencia sexista.

Los objetivos fundamentales de la LPIVG son de facilitar la continuidad de la actividad profesional de las trabajadoras víctimas de violencia de género, sin olvidar la necesidad de paliar los efectos que en el desarrollo de la misma pudieran ocasionarse por dicha circunstancia, atendiendo a las repercusiones que pueden causar en la prestación de servicios las alteraciones en la salud física o psicológica ocasionadas por la situación de maltrato, así como la adaptación de ciertas condiciones de trabajo en aras a garantizar la seguridad de las víctimas o el acceso de éstas a los servicios de apoyo, asesoramiento, prestaciones e incluso la tramitación de denuncias o de procedimientos de separación o divorcio, entre otras gestiones relacionadas con las situaciones de agresión.

Las bajas, el absentismo, las incapacidades y el descenso de la productividad que se da entre las mujeres víctimas de malos tratos han hecho necesaria la articulación de toda una serie de pautas legislativas específicas para, por un lado, hacer efectiva la protección de este colectivo, y, por otro, sensibilizar a los empresarios y a los interlocutores sociales sobre la magnitud del problema, con el fin último de evitar que se sucedan los despidos o la imposición de otro tipo de sanciones (BLASCO JOVER, 2005, p.104), no en vano de todos es sabido que 
"el trabajo remunerado mejora la posición de las mujeres en la familia, les hace menos dependientes social y económicamente y reduce su situación de vulnerabilidad ante la violencia” (ALBERDI y MATAS, 2002, p. 4).

Resulta muy acertado, por ende, que en una Ley de Medidas de Protección Integral contra la Violencia de Género se aborden aspectos laborales y de protección social, modificando el Real Decreto Legislativo 1/1995, de 24 de marzo, por el que se aprueba el texto refundido del Estatuto de los Trabajadores (ET), el Real Decreto Legislativo 1/1994, y de la Ley General de la Seguridad Social (LGSS), a fin de facilitar a las afectadas el acceso al empleo o la posibilidad de continuar su relación laboral, conciliándola con su derecho a la asistencia social integral y a la efectividad de la orden de protección, a través del reconocimiento del derecho a la reducción o reordenación del tiempo de trabajo, movilidad geográfica, cambio de centro de actividad, suspensión de la relación laboral y, en último término, extinción voluntaria a instancias de la interesada del vínculo contractual con ciertas ventajas (SEMPERE NAVARRO, 2005, pp.87 y ss.).

No se puede negar que la toma en consideración de la situación laboral de la mujer como un factor a tener en cuenta a la hora de ofrecerle una protección eficaz y completa, tiene una trascendencia innegable (MENÉNDEZ SEBASTIÁN y VELASCO PORTERO, 2005, p. 9). La LPIVG --con buena lógica-- trata de imponer a la organización empresarial una racionalidad adicional a la meramente profesional, para incluir en sus decisiones la toma en consideración de circunstancias puramente personales de las trabajadoras víctimas de maltrato a su servicio, que afectan a su rendimiento laboral o que pueden aconsejar cambios en su prestación, priorizando la tutela de la mujer trabajadora frente a las necesidades de la entidad productiva (FERNANDEZ LOPEZ, 2005, p.23). Ahora bien, la regulación de los derechos laborales de las víctimas, combinada con un elenco de incentivos a la contratación, de protección social o de ayudas económicas de otra naturaleza, admite no sólo elogios sino también algunas críticas, pues su configuración resulta en ocasiones un tanto compleja e incluso incoherente, pudiendo detectarse, al tiempo, serias lagunas o importantes vacíos de regulación.

\subsection{La Apuesta por el Mantenimiento de la Relación Laboral}

Resultaría ciertamente difícil lograr el carácter integral de la protección pretendida por la LPIVG si el legislador no atendiera a las repercusiones de la violencia de género en un ámbito vital tan determinante como es el desempeño laboral. En ocasiones, los deberes profesionales de la víctima de violencia de género pueden acabar por atraparla en una especie de "tela de araña” en la que el trabajo, aun suponiendo para la mujer la única vía de independencia económica respecto de su agresor, la encadena, a la vez, a un entorno y unas rutinas que, conocidas por aquél, pueden suponer para ella un mantenimiento o, 
incluso, una agravación del riesgo de ataque. De ahí la importancia de las disposiciones que permiten el desempeño flexible de la actividad profesional, de cara a la prevención o evitación de posteriores agresiones, en lo que se puede denominar una "virtualidad preventiva de segundo grado" o, dicho de otro modo, coadyuvando a neutralizar la violencia ya ejercida y sus efectos (GARRIGUEZ GIMÉNEZ, 2009, p. 56).

Las medidas de flexibilización de las obligaciones de trabajo se escalonan entre sí en una secuencia de intensidad creciente, que va desde la mera reordenación de la dedicación horaria, hasta la suspensión del contrato, pasando por la movilidad geográfica de la trabajadora. Como consideraciones previas y notas comunes a todas estas previsiones que reducen en parte sus bondades, cabe destacar, de un lado, cómo parecen dirigirse a trabajadoras con contratos de duración indefinida y a jornada completa, nada más lejos de la realidad actual, marcada por una intensa crisis económica, donde las mujeres sufren altos niveles de temporalidad, parcialidad y precariedad en la contratación, lo cual motiva una falta de operatividad de la regulación legal. De otro, que aun cuando se recogen en normas heterónomas, existe, sin duda, un espacio no desdeñable para que la negociación colectiva concrete y clarifique su aplicación práctica, si bien el tratamiento que sobre esta materia han efectuado los interlocutores sociales no deja de ser algo decepcionante, salvo honrosas excepciones, circunstancia que no ha mejorado en el contexto de recesión actual y de elevado índice de desempleo.

\subsection{Reordenación del Tiempo de Trabajo}

De acuerdo con lo previsto en la versión que la LPIVG proporciona al art. 37.7 ET, la trabajadora víctima de violencia de género tendrá la posibilidad, para hacer efectiva su protección o su derecho a la asistencia social integral, de proceder a la reducción de la jornada con disminución proporcional del salario (sin que se establezca límite mínimo o máximo) o a su redistribución. Esta medida se define de una forma amplia, al poder abarcar tanto la minoración del tiempo de actividad (sin que se añada el calificativo "diario" como se hace para el cuidado de hijos o familiares), cuanto la adaptación del horario, pasando por la aplicación del horario flexible. Resulta interesante resaltar que, aunque sea en términos genéricos, gracias a la expresión añadida (junto al horario flexible) en el art. 37.7 ET relativa a "otras formas de ordenación del tiempo de trabajo", este precepto, y como fórmulas de flexibilización del horario, está abriendo la puerta a situaciones tales como el "trabajo a tarea", el "teletrabajo" (versión actual del trabajo a domicilio o a distancia) o incluso a fórmulas mixtas que combinen la prestación laboral de servicios realizada de "forma presencial" con actividades de tipo "no presencial".

Sin embargo, en este ámbito cabe introducir, ya de entrada, un doble matiz: por una parte, parece partirse de la idea de que esas fórmulas de reordenación del tiempo de 
trabajo van a ser siempre posibles, con independencia del tipo de tarea que se desarrolla e incluso del tipo de empresa en el que se prestan servicios (desconociendo que las opciones van a ser muy distintas, en función, por ejemplo, de la dimensión de la organización productiva); por otra, parece limitarse la medida a las formas de ordenación del tiempo de actividad que ya se utilicen en la empresa, por lo que puede descartarse que el empresario tenga la obligación de poner en marcha este tipo de fórmulas si no las tenía implantadas con anterioridad (GALA DURÁN, 2005, p. 38).

Aun cuando han empezado a promulgarse sentencias favorables a los intereses de las trabajadoras en cuanto a la concreción de la reducción o reordenación horaria (STCo 3/2007, de 15 de febrero), en realidad, todas las manifestaciones de este derecho requieren de una compatibilidad con la organización del proceso productivo en la concreta entidad empresarial. Si en esa empresa no funciona un sistema de turnos, la víctima de violencia no podrá pedir que se le reconozca la facultad de ocupar uno u otro turno, lo mismo si no existe horario nocturno y diurno, o si no se prevé horario con franja de presencia, jornada intensiva, acumulación de horas, horario libre o márgenes de cortesía. Igualmente, la prerrogativa de cambio horario dependerá directamente de las condiciones particulares del puesto que ocupa, pues la modificación que la mujer propone no podrá afectar a sus quehaceres esenciales o a las funciones propias de su plaza. Precisamente por ello, hubiese sido interesante que la Ley concediese a la víctima la posibilidad de un cambio de puesto de trabajo (movilidad funcional) dentro de su grupo profesional.

En todo caso, esta incompatibilidad entre la organización del trabajo o las características del puesto que ocupa la trabajadora y la reordenación que ésta solicita tiene que ser absoluta, en el sentido de imposibilidad total de atender a los requerimientos de la agredida. No debe bastar, a tal efecto, con que la medida solicitada ocasione algún trastorno a la empresa, perjudique levemente los intereses empresariales o exija un especial celo organizativo; la enorme relevancia del bien jurídico protegido y la especial debilidad de la víctima resultan suficientes para demandar de la entidad empresarial un esfuerzo razonable de adaptación (MENENDEZ SEBASTIAN y VELASCO PORTERO, 2006, p. 75).

Para el ejercicio de los derechos de reordenación del tiempo de trabajo se establecen, además, dos alternativas, una acordada con la empresa y otra legal a falta de acuerdo (LOUSADA AROCHENA, 2005, p. 750). De conformidad con la primera posibilidad, tales derechos se podrán ejercitar en los términos que para estos supuestos concretos se establezcan en los convenios colectivos o en los acuerdos entre la empresa y la trabajadora afectada, de modo que el trato individual sólo debe admitirse si no hay convenio o pacto colectivo o si, habiéndolo, se limita a mejorar su contenido, no a acordar empeorando. Es particularmente significativo este llamamiento a los convenios colectivos o acuerdos de empresa para regular el derecho aquí analizado, pues, de esta forma, se obliga a incluir en la negociación colectiva propuestas --hasta ahora ciertamente escasas-- para erradicar o paliar 
los efectos de la violencia de género (BLASCO JOVER, 2005, p. 105). No hubiera sido desaconsejable, sin embargo, incluir en la Ley unos términos mínimos de ejercicio del derecho introducido en el art. 37.7 ET, sin perjuicio de su tratamiento por los convenios colectivos o los acuerdos que se alcancen en esta materia (FERRADANS CARAMES, 2005, p. 111). En todo caso, a falta de pacto, la concreción de estos derechos corresponderá a la propia trabajadora, que será quien decida en qué proporción y con qué régimen horario va a reducir su jornada laboral o las adaptaciones que considere necesarias para hacer efectiva su protección o su derecho a la asistencia social integral, con el límite lógico de su jornada ordinaria.

Con todo, la remisión que se efectúa al procedimiento previsto en el art. 139 Ley 36/2011, de 10 de octubre, reguladora de la jurisdicción social (LRJS), para resolver las discrepancias entre la víctima de violencia de género y el empresario implica que éste pueda negarse a aceptar la solicitud efectuada con la demora que ello conlleva en cuanto a la efectividad de los derechos protegidos. La solución acogida por la LRJS --la posición de demandante corresponde a la trabajadora, vetando el ejercicio inconsentido del derecho-no parece la más adecuada cuando lo que está en juego es la protección de intereses tan fundamentales como el derecho a la vida y a la integridad física de la mujer, que pueden requerir la adopción de medidas de carácter urgente (MARTIN PUEBLA, 2005, p. 24). "Probablemente, dada la situación en que se encuentra la trabajadora víctima de violencia de género, la necesidad de garantizar su protección integral y la asistencia social que precise y, sobre todo, evitar situaciones de riesgo, hubiera sido necesario declarar expresamente la inmediata ejecutividad de la decisión sin perjuicio de la posterior resolución judicial de las discrepancias entre ésta y el empresario" (DE LA PUEBLA PINILLA, 2005, p. 96).

Obsérvese, además, que la versión inicial de la LPIVG excluía a la reducción de la jornada (admitida como derecho de la trabajadora víctima de la violencia de género en el art. 21.1. LPIVG y en el art. 37.7 ET) de una posible generación de un derecho a desempleo, que sería parcial, al no contemplarse en el art. 21.1 LPIVG; exclusión ratificada, en aquel momento, con la letra no modificada del art. 203.3.II LGSS, donde se exigía, para acceder al desempleo parcial, una autorización en expediente de regulación de empleo que, en la reducción de jornada motivada por violencia de género, no concurre. Ante tan deplorable realidad, no corregida actualmente, y con el fin de prever una cierta solución económica para estos supuestos en favor de las víctimas de violencia de género" (GARCIA NINET, 2005, p. 6), que van a ver disminuidos sus ingresos precisamente en un momento en el cual previsiblemente aumentan los gastos, no en vano en muchas ocasiones las trabajadoras pasan a asumir de forma unilateral ciertas responsabilidades familiares (QUINTANILLA NAVARRO, 2005, p. 40), la LOIEMH introduce un nuevo párrafo $5^{\circ}$ en el art. 211 LGSS, en virtud del cual "en los supuestos de reducción de jornada previstos en los apartados 4 bis, 5 y 7 del art. 37 ET, para el cálculo de la base 
reguladora, las bases de cotización se computarán incrementadas hasta el 100 por 100 de la cuantía que hubiera correspondido si se hubiera mantenido, sin reducción, el trabajo a tiempo completo o parcial. Si la situación legal de desempleo se produce estando la trabajadora en las situaciones de reducción de jornada citadas, las cuantías máxima y mínima se determinarán teniendo en cuenta el indicador público de rentas de efectos múltiples en función de las horas trabajadas antes de la reducción de la jornada” (MARTÍNEZ LUCAS, 2010, p. 1009).

Es más, aun cuando la jurisprudencia ya venía siendo sensible a este problema, la LOIEMH se esfuerza en dejar claro que los criterios para el cálculo de indemnizaciones por despido cuando la trabajadora haya tenido reducida previamente su jornada por razones de violencia de género deben tener en cuenta la remuneración de la víctima anterior al disfrute de la reducción de la jornada (disposición adicional 18 $\mathrm{ET}$ ).

Desde una perspectiva crítica sorprendía y sorprende, todavía al día de hoy, el hecho de que, aun cuando el art. 19 LPIVG regula también el derecho a la asistencia social integral de los menores que se encuentran bajo la patria potestad o guarda y custodia de la trabajadora, ésta no puede solicitar las medidas seńaladas en este apartado para garantizar el derecho a la asistencia social de aquéllos (y poder acompañarlos, por ejemplo, en caso de que requieran atención psicológica), ya que la norma legal sólo las prevé para garantizar el ejercicio efectivo del derecho a la asistencia social de la propia mujer en exclusiva.

\subsection{Movilidad Geográfica}

Conforme a la redacción introducida en el art. 40.3 bis ET por la LPIVG, la trabajadora, que se vea obligada a abandonar su puesto de trabajo en la localidad donde venía prestando sus servicios para hacer efectiva su protección o su derecho a la asistencia social integral, tendrá derecho preferente a ocupar otro puesto, del mismo grupo profesional o categoría equivalente, que la empresa tenga vacante en cualquier otro centro de trabajo. El ámbito de protección dispensado por la norma es doble, admitiendo la novación locativa con o sin cambio de residencia, pues no cabe duda que la trabajadora, víctima de maltrato, podrá tener interés en trasladarse a un centro de trabajo que implique el traslado de su domicilio a otra localidad distinta, pero en otros casos su pretensión puede consistir en prestar servicios en otra zona que, por su cercanía u otras razones, asegure con más garantía sus desplazamientos (ARAMEDI SANCHEZ, 2005, p. 65).

La iniciativa para poner en marcha estas medidas corresponde a la propia mujer, cuando considere que son necesarias para hacer efectiva su protección o su derecho a la asistencia social integral y, probablemente, recurrirá a ellas en los casos en que la reducción de la jornada o la reordenación del tiempo de trabajo no resultan suficientes para hacer frente a la concreta situación de amenaza en que se encuentra. El empresario no puede 
negarse a la petición de movilidad de ésta, pero podrá exigir que acredite su situación mediante la correspondiente orden de protección o, excepcionalmente, a través del informe del Ministerio Fiscal que indique la existencia de indicios de que la trabajadora es víctima de violencia de género. Atendiendo a la importancia del bien jurídico protegido, la trabajadora tendrá preferencia "frente a otros derechos como el de movilidad voluntaria de los trabajadores a tiempo parcial [art. 12.4 e) ET], el derecho de consorte (art. 40.3 ET) o, incluso, el derecho preferente a ocupar una plaza vacante del excedente voluntario (art. 46.5 ET)" (LOUSADA AROCHENA, 2005, p. 752), pero, previsiblemente, en caso de que no exista posibilidad de ocupar un nuevo puesto vacante, y dado que la trabajadora tiene que abandonar el que venía desempeñando, en la práctica se producirá la interrupción temporal de la relación laboral en los términos que se comentarán con posterioridad.

La duración de la movilidad locativa será de seis meses dentro de los cuales la empresa tiene la obligación de conservar el puesto de trabajo anteriormente ocupado (MOLINA NAVARRETE, C., 2005, p. 20). Transcurrido ese plazo, la víctima de violencia de género podrá optar por reincorporarse o continuar en su nuevo puesto, decayendo la obligación de reserva, a salvo por supuesto de las mejoras que en la configuración de este derecho pueda incorporar la autonomía colectiva o el acuerdo más favorable entre las partes. Nada dice, sin embargo, la LPIVG acerca de la intervención del juez en la determinación de posibles prórrogas de la situación del cambio de centro de trabajo o de localidad, a diferencia de lo que contempla en cuanto a la suspensión del contrato, lo cual no deja de ser incoherente si se tiene en cuenta que, tanto una medida como la otra, tienen la finalidad de garantizar la integridad de la víctima.

A efectos de posibilitar el ejercicio del derecho aquí analizado, la empresa está obligada a comunicar individualmente a la trabajadora las vacantes existentes o las que se pudieran producir en el futuro, no siendo suficiente la utilización del tablón de anuncios. Este deber de aviso tiene gran trascendencia, pues en la mayoría de los casos la necesidad de la trabajadora será urgente y sin la colaboración de la empresa carecerá de efectividad. De esta forma, si el empresario no cumpliera con tal deber de información y ocupara la plaza con otro trabajador previamente vinculado a la empresa o contratado al efecto, la víctima de violencia de género podría reclamar en vía judicial a través de la modalidad procesal de tutela de derechos fundamentales, solicitando la asignación del puesto como forma de reposición del derecho vulnerado (arts. 177 y ss. LRJS).

Cuando, por razones de seguridad, sea acuciante la necesidad de cambiar de centro de trabajo y ello no sea posible por no existir vacante o porque las concurrentes no son del mismo grupo profesional o categoría equivalente, o porque aun existiendo el empresario no la ofrece a la trabajadora, las únicas vías que se abren son, en primer lugar, la posibilidad de suspender su relación laboral en los términos que se analizarán seguidamente, y, en segundo lugar, la solicitud de excedencia voluntaria (de duración no menor a cuatro 
meses y no mayor a cinco ańos), siempre que la trabajadora cuente con una antigüedad en la empresa al menos de un año, manteniendo en este caso únicamente "el derecho preferente al reingreso en las vacantes de igual o similar categoría a la suya que hubiera o se produjeran en la empresa”, y no pudiendo ser instada otra vez hasta que transcurran "cuatro años desde el final de la anterior excedencia", situación esta última que no conlleva el derecho a prestaciones por desempleo, causando baja en el régimen de la Seguridad Social correspondiente (FARALDO CABANA, 2012, p. 151).

\subsection{Suspensión Contractual}

La LPIVG reconoce a la trabajadora víctima de violencia de género otra serie de facultades dirigidas a compatibilizar, en la medida de lo posible, el mantenimiento de su empleo con su integridad personal, evitando así decisiones extremas o perjudiciales. A tal fin, el art. 45.1.n) ET permite a la afectada interrumpir su contrato de trabajo por su propia iniciativa y decisión, sin quedar supeditada al beneplácito empresarial y sin especiales exigencias formales o de fondo, como pudieran ser las de preavisar con una concreta antelación, contar con una antigüedad mínima o estar vinculada con carácter indefinido o a tiempo completo (RODRIGUEZ ESCANCIANO, 2013, pp. 98 y ss.).

La finalidad que persigue el legislador con esta medida es doble: por un lado, facilitar la protección eficaz de la víctima, eliminando cualquier aspecto previsible (como es el puesto de trabajo) que pudiera provocar un ataque del agresor; por otro, promover una recuperación física y psicológica más rápida para la trabajadora, eximiéndola del deber de asistencia y puntualidad en el trabajo, sin que pueda incrementar la inestabilidad emocional.

En consecuencia, dos son los únicos requisitos que condicionan el válido ejercicio del derecho: por una parte, acreditar la circunstancia habilitante mediante la orden judicial de protección o, excepcional e indiciariamente, a través de informe del Ministerio Fiscal; por otra, la necesidad y conveniencia del abandono temporal de su puesto, a interpretar muy flexiblemente por la dificultad para su prueba. En principio, es la propia mujer quien elige su duración por un tiempo de hasta seis meses, pudiendo ser prorrogada por períodos de tres meses, hasta completar dieciocho, cuando así lo decida el juez competente y la efectividad de su salvaguarda lo exija (MATEU CARUANA, 2007, pp. 99 y ss.) Se trata, en realidad, de un supuesto de excedencia forzosa, en el que queda garantizada la reincorporación siempre que se ajuste a la duración máxima especificada por el legislador. Ahora bien, cuando la suspensión exceda de ese tiempo, es lógico presuponer que tal situación pasaría a calificarse como un mero ejemplo de excedencia voluntaria, solicitada por motivos personales y que únicamente dará lugar a un derecho preferente al reingreso a las vacantes que existan o se puedan producir en el futuro en la empresa. 
Como contrapartida a la pérdida de ingresos provocada por una situación no deseada por la trabajadora, la consecuente reserva de su puesto se conjuga con una amplia cobertura social --significativamente, prestaciones por desempleo total (art. 208.1.2 LGSS)--, "perfil necesario cuya ausencia determinaría la ineficacia del conjunto", quedando atemperadas, al tiempo, las obligaciones derivadas del compromiso de actividad. Los datos personales de la trabajadora serán custodiados con especial cautela por los Servicios de Empleo y tendrán un acceso restringido. Es más, si la mujer desea mantener la reserva sobre su domicilio podrá facilitar uno alternativo o indicar un apartado de correos donde recibir las comunicaciones. Para el percibo de la prestación por desempleo, la trabajadora debe aportar una comunicación del empresario en la que conste que la trabajadora ha ejercitado el derecho a la suspensión. Si éste se negase a entregarla, ésta podrá igualmente adjuntar denuncia ante la Inspección de Trabajo del incumplimiento empresarial.

En todo caso, se subordina la prestación de la Seguridad Social a la obtención de la orden de protección o el informe del Ministerio Fiscal (disposición adicional 42a LGSS). El primer instrumento incluye tanto el supuesto en que se dicta un auto en fase de instrucción penal acordando dicha orden (art. 544 ter Ley de Enjuiciamiento Criminal), como cuando se dicta sentencia penal que incluye una orden de alejamiento (art. 57.2 en relación con el art. 48.2 Código Penal), en cuyo caso sustituye y cumple la función de aquélla. El alejamiento es una de las medidas cautelares del orden penal que se pueden adoptar en la orden de protección. Si se dicta una sentencia penal condenatoria por un delito relativo a violencia de género que incluya dicha orden de alejamiento, también se tratará de un medio de prueba hábil para acreditar la violencia de género a efectos de la prestación por desempleo. El problema surge cuando una solicitante de la prestación de desempleo no haya obtenido una orden de protección ni informe del Ministerio Fiscal, pero pretende acreditar su condición de víctima de violencia de género utilizando cualquier otro medio de prueba, aplicando el principio pro beneficiario. En contra de esta tesis, habría que invocar el tenor literal de la norma, cuya justificación radica en la búsqueda de la seguridad jurídica, que no regula una prestación por desempleo para víctimas de violencia de género, sino una prestación por desempleo para víctimas de violencia de género que hayan conseguido una orden de protección o un informe del Ministerio Fiscal.

Teniendo en cuenta que ni la letra h) del apartado 1 del art. 45, ni la letra g) del art. 48 ET, establecen que la interrupción temporal del contrato sólo pueda ser solicitada una vez, es pensable que tras finalizar dicha suspensión y reincorporarse la trabajadora, ésta pueda ser de nuevo víctima de violencia de género e iniciar una nueva interrupción que, a su vez, generaría derecho a prestaciones de desempleo, ya que se computan las mismas cotizaciones que sirvieron para generar las prestaciones de la primera. De todo ello cabe deducir, a pesar de la compleja redacción empleada por la LPIVG, que: primero --y como excepción a la regla general--, el período de cotización tenido en cuenta para reconocer el 
derecho a una prestación por desempleo contributiva o asistencial en un caso de suspensión del contrato por violencia de género no se agota y, por tanto, podrá computarse nuevamente para tener derecho a prestaciones futuras; segundo, el tiempo durante el cual se percibe el desempleo obrante la suspensión del contrato se considerará, también como excepción, cotizado a los efectos de percepciones futuras por esta misma contingencia. Con estas medidas se logra, en definitiva, que el acceso a la protección por desempleo durante el tiempo de suspensión del contrato tenga un coste cero para la trabajadora maltratada y tampoco suponga gastos adicionales para el empresario, máxime cuando este período de suspensión con reserva de puesto de trabajo "tendrá la consideración de período de cotización efectiva a efectos de las correspondientes prestaciones de Seguridad Social por jubilación, incapacidad permanente, muerte o supervivencia, maternidad y desempleo" (art. 124.5 LGSS). A mayores --y como ya consta--, se permite la contratación interina en sustitución de la trabajadora sin coste para la empresa (VILA TIERNO, 2009, p. 274). Ha de advertirse, no obstante, que la duración de la prestación por desempleo puede no llegar a cubrir todo el período suspensivo, al depender su extensión temporal, de acuerdo con las exigencias generales, del historial de cotización.

\subsection{Conclusión del Contrato a Instancias de la Trabajadora y Nulidad del Despido}

Si la víctima considera que la violencia padecida no le permite continuar con la relación laboral, la Ley también avala la extinción de la misma en las mejores condiciones posibles, defendiéndola, al tiempo, frente a cualquier represalia empresarial por el ejercicio de sus específicos derechos laborales.

La LPIVG ańadió una letra m) al art. 49.1 ET para contemplar la extinción por "decisión de la trabajadora que se vea obligada a abandonar definitivamente su puesto de trabajo como consecuencia de ser víctima de violencia de género”. La previsión específica y separada no impide configurar esta nueva modalidad como un supuesto más de dimisión, si bien ha de ser calificada como sui generis en virtud de las importantes y beneficiosas singularidades que presenta, pues frente a la versión genérica, quienes presten servicios por cuenta ajena y sean objeto de estos deleznables comportamientos podrán resolver su vínculo sin necesidad de observar preaviso alguno y quedando en situación legal de desempleo [art. 208.1.1.e) LGSS], para lucrar, en su caso, las oportunas prestaciones (QUIROS HIDALGO, 2008, pp. 1324 y ss.). Esta posibilidad, que ha sido muy favorablemente acogida, se explica porque el presupuesto extintivo no es la plena voluntariedad, sino la concurrencia de una situación singular que obliga a la trabajadora a adoptar la decisión extintiva por la violencia en la que se encuentra inmersa y la necesidad de un largo período para la recuperación (CEINOS SUAREZ, 2008, p. 98). Ante el silencio legal sobre la forma a utilizar para trasladar al empresario la decisión extintiva, 
bastará cualquier medio válido en Derecho. Sin embargo, resulta harto recomendable su documentación para certificar el ejercicio del derecho ante eventuales negativas de la contraparte, la cual queda obligada a realizar una comunicación escrita al Servicio Público de Empleo, requisito imprescindible para acreditar la situación legal de desempleo. Así pues, la conducta del empresario no pasa únicamente por asumir pasivamente la decisión extintiva de la trabajadora (que tampoco requiere confirmación judicial), porque junto a la descrita puede alcanzar un protagonismo adicional: en efecto, como declaración de voluntad recepticia, el desistimiento de la víctima no admite retracto, salvo cuando el empleador permita y consienta la reconsideración de forma tal que todo continúe desarrollándose cual si nada hubiere acaecido. No cabe ocultar, sin embargo, el riesgo relativo a que la voluntad extintiva de la trabajadora derive del temor a sufrir una nueva agresión.

De otro lado, no procede olvidar tampoco la garantía de indemnidad a favor de la mujer víctima de violencia, auténtico seguro frente al empresario de un pacífico y solvente ejercicio de los derechos laborales y de Seguridad Social reconocidos en la LPIVG, que supone el reconocimiento de la nulidad del despido disciplinario carente de causa y del despido objetivo cuando se produzca respecto de aquellas mujeres agredidas que acrediten tal condición y que hayan ejercido los derechos de reducción o reordenación de su tiempo de trabajo, de movilidad geográfica, de cambio de centro de actividad o de suspensión de la relación laboral [arts. 55.5 b) y 53.4 b) ET]. Su efecto será la lógica readmisión inmediata de la mujer con el abono de los salarios dejados de percibir (ARAMEDI SANCHEZ, 2005, p. 68). Esta medida reporta cuantiosas ventajas para las víctimas de maltrato, pues únicamente deben acreditar el ejercicio de alguno de los derechos reconocidos en la LPIVG para merecer la protección aquí analizada, correspondiendo al empresario probar la rectitud y legalidad de su decisión de dar por extinguido el contrato. Debe quedar claro, no obstante, que no se trata de una garantía de permanencia preferente general en la empresa, pues sólo se impone la declaración de nulidad -impidiendo la improcedenciacuando el empresario no es capaz de probar la razón económica, técnica, organizativa o de producción en que fundó el despido objetivo o el incumplimiento grave y culpable imputado en el caso de despido disciplinario, pues si acreditara la concurrencia de tales extremos, necesariamente ajenos al ejercicio por la víctima de sus derechos laborales, tal despido deberá ser calificado por el juez como procedente.

A la luz de lo anterior, tampoco sería desaconsejable la inclusión de alguna indicación expresa sobre la nulidad de cualquier sanción --diferente al despido-- que traiga su origen en el ejercicio de los derechos reconocidos a la trabajadora víctima de violencia de género, aunque dicha calificación no admite duda, no sólo porque se estaría castigando a la mujer por la activación de un derecho legalmente reconocido, sino también por la discriminación por razón de género que la misma escondería en tanto que sólo las féminas son titulares de estos derechos específicos. 
Sin abandonar el tono crítico adoptado y teniendo en cuenta la vinculación directa entre el ejercicio de los derechos derivados de la condición de víctima de violencia de género y la nulidad cualificada del despido, parece que esta protección no alcanza tampoco a aquellas mujeres que, a pesar de estar sufriendo violencia machista, no han optado por ejercer los derechos reconocidos en la LPIVG. Aun cuando, en este caso, un despido que tuviese su fundamento en la situación de violencia sexista padecida por una trabajadora deberá ser calificado, igualmente, como nulo por discriminatorio, lo cierto es que es necesario aportar por la víctima de violencia de género --y precisamente aquí es donde surgen los problemas-- indicios razonables del trato arbitrario, lo cual no siempre es fácil para la trabajadora, convirtiéndose, en ocasiones, en una auténtica probatio diabólica (RODRIGUEZ ESCANCIANO, 2002, pp. 366). Hubiese sido de gran interés, por tanto, que la Ley hubiese incorporado alguna indicación sobre el rendimiento debido por la empleada víctima de violencia de género que ni suspende ni extingue su relación contractual, similar a la que se contiene en el art. 20.3 ET para los trabajadores discapacitados, respecto de los cuales el control y vigilancia empresarial del cumplimiento de sus obligaciones laborales debe realizarse teniendo en cuenta su capacidad real, no en vano la tensión emocional a la que quedan sometidas estas trabajadoras provocará una posible --y lógica-- merma de su productividad.

La nulidad del despido, claro es, no implica que las trabajadoras sean inmunes frente al poder disciplinario de la empresa con carácter absoluto; sus incumplimientos contractuales siguen siendo sancionables y, por eso, el último párrafo del art. 55.5 ET indica que en todos estos supuestos hay que calificar el despido como nulo "salvo que se demuestre su procedencia” (SEMPERE NAVARRO y BARRIOS BAUDOR, 2006, p. 493). No cabe entender, por tanto, que la víctima queda blindada de modo infranqueable, de tal suerte que toda coincidencia entre violencia de género y extinción del contrato determine automática e inexorablemente la nulidad de la decisión. Así, el cumplimiento de la condición resolutoria o la llegada del término final pactado deberían permitir al empresario dar por terminado legítimamente el contrato, salvo que concurra algún dato indiciario de la existencia de discriminación como pudiera ser la posterior contratación de otro trabajador/a para que realice las mismas funciones que la cesada, pues, en tal caso, quedará evidenciada la necesidad de continuar cubriendo dichas funciones y, por ende, deviene objetivamente ilógica la no continuidad en la empresa de la trabajadora. Ante tales indicios, al empresario correspondería la carga de probar (por inversión del mecanismo probatorio) la razonabilidad y objetividad de la decisión de no renovación.

Por otra parte, respecto de la posibilidad de optar por la resolución judicial indemnizada a instancias de la víctima al amparo del art. 50 ET, cabe señalar que podrá solicitarse cuando la violencia de género se sufre en el marco de la propia relación laboral por ser precisamente el empresario el varón con el que se ha sostenido o se sostiene una relación de pareja. Esta vía permite la obtención de una indemnización tasada equivalente a la del 
despido improcedente (actualmente, 33 días de salario por año de servicio con el máximo de 24 mensualidades) y otra adicional por vulneración de derechos fundamentales.

En fin, problemas particulares se plantean cuando víctima y ofensor trabajan en el mismo centro de trabajo y la mujer posee una orden de alejamiento que puede ocasionar serios problemas organizativos, sobre todo, si la empresa es pequeńa o tiene un único centro de trabajo. En tales supuestos, es difícil apostar por una solución general que abogue por la extinción automática del contrato por ineptitud sobrevenida del agresor, debiendo valorar en cada caso las circunstancias concretas.

\subsection{Justificación de las Faltas de Asistencia o Puntualidad}

No todas las medidas laborales aplicadas sobre las mujeres víctimas de violencia de género están orientadas a facilitar su alejamiento del agresor. En ciertas ocasiones, se trata de evitar que el cumplimiento de las obligaciones inherentes a la relación laboral obstaculice la recuperación física o psíquica que precisan las víctimas de este tipo de violencia. Así, se van a considerar justificadas y no se podrán tener en cuenta aquellas ausencias o faltas de puntualidad que se deban al padecimiento, físico o psíquico, generado por situaciones de violencia sexista a efectos de un despido objetivo por absentismo [art. 52 d) ET], de posible aplicación en los supuestos de "faltas de asistencia al trabajo, aun justificadas pero intermitentes, que alcancen el $20 \%$ de las jornadas hábiles en dos meses consecutivos siempre que el total de faltas de asistencia en los doce meses anteriores alcance el $5 \%$ de las jornadas hábiles, o el $25 \%$ en cuatro meses discontinuos dentro de un periodo de doce meses". Esta previsión otorga un trato especial a las faltas de asistencia al trabajo imputables a una situación objetiva de violencia de género, asimilándolas a otros supuestos de no presencia especialmente protegidos, para sortear la paradoja de que el ejercicio de derechos vinculados a la protección de intereses vitales, como la vida o la integridad física de la fémina amenazada, termine perjudicando a la propia mujer en el plano laboral al privarla eventualmente de un empleo (MARTIN PUEBLA, 2005, p. 26). Entre dichas faltas habrán de entenderse incluidas las necesarias para realizar los trámites de asistencia letrada, presentarse a las comparecencias judiciales, acudir a consultas de tratamiento psicológico o normalizar la situación de la víctima con motivo de cambio de domicilio o de residencia.

No obstante, dichas ausencias, para considerarse justificadas, deben estar debidamente acreditadas por los servicios sociales de atención o servicios de salud, previa expedición de los correspondientes documentos pertinentes. Por tanto, las trabajadoras deberán entregar al empresario el certificado que les haya expedido el servicio público, en el que se constata que su situación física o psicológica justifica las ausencias o faltas de puntualidad. Dicho documento operaría de forma similar a los partes de incapacidad temporal 
o confirmación de la citada incapacidad temporal, que justifican las ausencias de los trabajadores por enfermedad común, accidente laboral o común o enfermedad profesional. No se admiten, sin embargo, otros medios de prueba como pudieran ser los informes de ONGs o Fundaciones (KAHALE CARRILLO, 2007, p. 1871). Hubiera sido necesario, no obstante, dar un paso más y proteger estas situaciones con el régimen más beneficioso previsto para los permisos retribuidos en el art. 37. 3 ET, pues, en otro caso, el empresario procederá lógicamente a descontar los salarios correspondientes a las ausencias en claro perjuicio de la trabajadora.

\subsection{Penalización a los Agresores en cuanto a Prestaciones de Seguridad Social se Refiere}

Razones fácilmente comprensibles, emparentadas tanto con las exigencias de la moderna victimología cuanto con tradicionales principios del sistema de Seguridad Social, explican que se haya prestado atención a la posición del agresor de la mujer y a sus eventuales derechos en materia de protección social (GARCA ROMERO, 2012, p. 132), evitando que el autor de un delito pueda beneficiarse de las consecuencias del mismo. Desde tal perspectiva, la disposición adicional $1^{\text {a }}$ LPIVG establece dos previsiones elusivas del derecho al percibo de pensiones de muerte y supervivencia por el agresor. Así, de un lado, quien fuera condenado, por sentencia firme, por la comisión de un delito doloso de homicidio en cualquiera de sus formas o de lesiones, cuando la ofendida por el delito fuera su cónyuge o excónyuge, perderá la condición de beneficiario de la pensión de viudedad que le corresponda dentro del sistema público de pensiones causada por la víctima, salvo que, en su caso, medie reconciliación entre ellos (GARCIA-ATANCE, 2012, p. 137).

Esta norma se aplica a los hijos comunes del agresor y la víctima, pero no a los hijos del agresor que no lo sean de aquélla. Si se priva al padre de la patria potestad se tendrá que nombrar un tutor, el cual administrará la pensión de orfandad. El problema se suscita cuando no se ha privado al padre de la patria potestad, entendiendo que igualmente el INSS debe proceder a tal nombramiento para que pase a percibir las prestaciones de los menores. Puede suceder, no obstante, que el agresor haya sido condenado por un delito de lesiones cometido en el pasado, sin privación de patria potestad, ni encontrase en la cárcel en el momento de fallecer la madre, razón por la cual no concurre ninguno de los supuestos que permiten el nombramiento de un tutor (art. 222 Código Civil). Si el padre está a cargo de los hijos menores, el hecho de privarle de la pensión de orfandad redundaría en perjuicio de los hijos. Cuestión distinta tiene lugar en un supuesto recientemente enjuiciado en el cual el agresor ha sido condenado como autor de un asesinato y ha sido privado de la patria potestad al ser la madre la que se ocupaba de todas las obligaciones parentales, quedando la hija en situación de desamparo total, equiparada a la de huérfana 
de ambos padres y merecedora, por tanto, de la prestación de orfandad absoluta (previo incremento de la pensión de orfandad simple del 20 al 52 por 100, a la luz de la SJS núm. 3 Almería 24 enero 2014).

Por otra parte, cabe cuestionar, como crítica, si una decisión privada como es la reconciliación puede abrir el acceso a una prestación del sistema de Seguridad Social que se cerró. La cuestión no es baladí, en tanto en cuanto la realidad se encarga de demostrar cómo "las situaciones de violencia no se denuncian, si se denuncian, se retira la denuncia, si no se retira la denuncia no se comparece en el juicio e, incluso, tras haberse dictado sentencia no es infrecuente que las víctimas acudan a los juzgados para pedir su no ejecución. Desgraciadamente, el miedo a represalias por parte del agresor y la dependencia económica respecto de éste pesan como factores determinantes de este tipo de reacciones, fundamentalmente entre los colectivos más vulnerables de mujeres" (QUINTANILLA NAVARRO, 2005, p. 56). Quizá fuera conveniente, por ende, supeditar el restablecimiento del derecho no a la reconciliación de los cónyuges (que puede ser aceptada por la víctima para evitar otros daños) sino a otras circunstancias como pudiera ser el cese efectivo y prolongado de cualquier acto de violencia contra la mujer, sea cual sea la relación que las partes mantengan en el futuro.

Es más y como objeción adicional, teniendo en cuenta que el derecho a la pensión no se extingue hasta que recae condena firme, en cierta medida se está incentivando también la recurribilidad por parte del agresor, algo que se puede evitar declarando que ya desde la situación penal de imputado o procesado por un delito de violencia de género va a quedar efectivamente en suspenso el percibo de la prestación, tal y como ha recogido el INSS en un reciente criterio (CAVAS MARTINEZ, 2006, p. 347).

En todo caso, la sentencia condenatoria ha de llegar a conocimiento de la entidad a la que corresponde el abono de las pensiones de viudedad y orfandad. De ello se ha ocupado el Real Decreto 660/2007, de 25 de mayo, por el que se modifica el Real Decreto $355 / 2004$, de 5 de marzo, que regula el registro central para la protección de las víctimas de violencia doméstica, entendiendo que el encargado de este registro debe de comunicar semanalmente a la entidad gestora los procedimientos terminados por sentencia firme condenatoria (FARALDO CABANA, 2012, p. 56).

De lo que no cabe duda, a la postre, es de la necesidad de extender esta prohibición a otras prestaciones como pudiera ser la de paternidad (LANDA ZAPIRAIN, 2007, 19). Únicamente, el art. 9 Real Decreto 295/2009, de 6 de marzo, por el que se regulan las prestaciones económicas del sistema de Seguridad Social por maternidad, paternidad, riesgo durante el embarazo y durante la lactancia natural, introduce ciertas excepciones en lo que afecta a las posibilidades de "opción a favor del otro progenitor" de la prestación por maternidad cuando se ha producido entre la pareja algún episodio de violencia de género. Así, si bien la regla general establece que "en el caso de que ambos progenitores 
trabajen el otro progenitor podrá percibir el subsidio por maternidad siempre y cuando la madre, al iniciarse el período de descanso por maternidad, haya optado porque aquél disfrute de una parte determinada e ininterrumpida del período de descanso posterior al parto, bien de forma simultánea o sucesiva con el de la madre", también se contempla que "dicha opción podrá ser revocada por la madre si sobrevinieren hechos que hagan inevitable la aplicación, tales como ausencia, enfermedad o accidente del otro progenitor, abandono de familia, separación, violencia de género u otras causas análogas" (art. 9.1). El legislador no hace más que plasmar en el texto de la norma una pauta lógica y razonable, puesto que obviamente constituiría una situación abusiva seguir disfrutando de un derecho ajeno en virtud de un acto inicial de cesión del titular cuando, de forma sobrevenida, la violencia de género hace cambiar sustancialmente la relación existente entre los progenitores (SELMA PENALVA, 2011, p. 1056).

\section{La Publicación de la Ley Brasileña 11.340/2006 - "Lei Maria da Penha" y su Inclusión en el Ordenamiento Jurídico Brasileño}

La República Federativa de Brasil, en su artículo $1^{\circ}$ enumera como fundamentos de la Constitución Brasileña la soberanía; la ciudadanía; la dignidad de la persona humana; los valores sociales del trabajo y de la libre iniciativa y el pluralismo político (BRASIL, CRFB/1988, traducción nuestra). Después, en su artículo $3^{\circ}$ expone los objetivos fundamentales de la República Federativa de Brasil, entre ellos, el de promover el bien de todos, sin prejuicios de origen, raza, sexo, color, edad y cualquier otra forma de discriminación (BRASIL, CRFB/1988, traducción nuestra).

También en su artículo $4^{\circ}$ adoptó como uno de sus principios el respecto a los derechos humanos (BRASIL, CRFB/88). Tanto es así, que Brasil ha ratificado muchos de los tratados internacionales y convenciones, incluyendo la Convención sobre la eliminación de todas las formas de discriminación contra las mujeres y la Convención Interamericana para prevenir, punir y erradicar la violencia contra la mujer - Convención de Belém do Pará.

La preocupación por la salud y la integridad física de las mujeres brasileñas que sufren algún tipo de violencia en el ámbito familiar pasó a concretarse en el año de 2006, con la promulgación de la Ley no 11.340/2006, bautizada de Ley "Maria da Penha”, por el presidente en ejercicio Luis Inácio Lula da Silva (BRASIL, LEI No 11.340/2006).

La Ley 11.340/2006 fue promulgada de acuerdo con el párrafo $8^{\circ}$ del artículo $226^{\circ}$ de la Constitución Brasileña, que prevé como deber del Estado prestar asistencia de forma especial a la familia, y a cada uno de los que la componen, creando mecanismos para cohibir la violencia de sus relaciones (BRASIL, CRFB/88, traducción nuestra). Al mismo tiempo que el Estado ofrece asistencia a la familia, buscará también proteger a la mujer 
contra toda y cualquier tipo de agresión o violación de su derecho a vida, libertad, salud, integridad física o psíquica.

Como dato a tener en cuenta, cabe señalar que se llama Ley "Maria da Penha" en homenaje a la Sra. Maria da Penha Maia Fernandes, farmacêutica y bioquímica que sufrió incontables agresiones y dos tentativas de homicidios de su marido, Marco Antônio Heredia Viveiros, colombiano, economista y profesor universitario, naturalizado brasileño. En la primera tentativa de homicidio, en 1983 fue un disparo que la dejó tetrapléjica. La segunda tentativa de homicidio fue cuando su marido tentó electrocutarla en la bañera, mientras se bañaba.

La Ley "Maria da Penha” es una Ley que demuestra que las mujeres merecen una protección especial al ser víctimas de la violencia doméstica, no pudiendo, por lo tanto, ser aplicada en beneficio del hombre, aunque sea este víctima de violencia doméstica. Tratándose de una Ley constitucional y que no afronta el principio de la igualdad (BRASIL, $5^{\circ}$ de la CRFB/88) pues la mujer y el hombre son iguales en la Ley (igualdad formal) cierto es que aporta un tratamiento desigual en virtud de su evidente desigualdad real (igualdad material).

Desde luego la protección que la ley "Maria da Penha" concede a la mujer tiene respaldo en los principios constitucionales de la dignidad de la persona humana (BRASIL, Art. $1^{\circ}$, III, CRFB/88) y de la igualdad en sentido material.

\subsection{Finalidad de la Ley $11.340 / 2006$}

Siendo la Ley 11.340/2006 totalmente recibida por la Constitución Brasileña y verificada su constitucionalidad, incumbe relatar cuales son las definiciones sobre la violencia y cuál es la finalidad principal de la Ley.

Las intenciones de Ley son visibles desde el artículo $1^{\circ}$, que además de tener como objetivo castigar y prevenir la violencia doméstica y familiar contra la mujer, dispone sobre la creación de juzgados especializados en violencia doméstica y familiar y establece medidas de asistencia y protección a las mujeres víctimas de violencia doméstica y familiar (BRASIL, Ley 11.340/2006).

Al observar el artículo $1^{\circ}$ y los demás preceptos de la Ley 11.340/2006, se puede decir que se trata de una ley multidisciplinar, por generar normas no sólo en la esfera penal - castigar al agresor --, como también en la esfera laboral -- artículo $99^{\circ}$--, además de aspectos civiles y de implantar políticas públicas de cuño social y asistencial.

En los artículos $7^{\circ}$ y $5^{\circ}$ de la Ley están definidas todas las formas de agresión contra la mujer, que configurara violencia doméstica y familiar. Es decir, la Ley "Maria da Penha" describe cuáles son las acciones consideradas como violencia doméstica -- art.7 -- cuando 
llevadas a efecto en el ámbito de las relaciones familiares o afectivas -- descritas en el art. 5० -- (DIAS, 2007, traducción nuestra).

El concepto de violencia expresado en la Conferencia de Bejing (1995) es más amplio que el traído por la Convención de Belém do Pará (1994), una vez que considera incluido cualquier acto de violencia de género, que resulte o pueda provocar un daño o sufrimiento de naturaleza física, sexual o psicológica, inclusive amenazas, coerción o privación arbitraria de la libertad que se produzcan en la vida pública o privada. (Cavalcanti, 2010, traducción nuestra).

La violencia de género corresponde al lado más cruel y visible de la desigualdad entre hombres y mujeres, ya que lleva al varón a creer que es superior a la mujer y por eso tiene derecho de controlarla, sojuzgarla, humillarla y agredirla de diversas maneras, por el simple hecho de hacerlo, por la diferencia de género (CAMPOS, 2011, traducción nuestra).

La Ley 11.340/2006 ha separado la violencia desde dos aspectos distintos, la primera practicada en el ámbito de la unidad familiar, en el ambiente doméstico o de intimidad (Art. 5) y la segunda practicada contra la mujer (Art.7º). Estos dos tipos de violencia y previstos en la Ley "Maria da Penha" autorizan a la víctima a utilizar este poderoso estatuto tuitivo que actuará extendiendo su protección a las mujeres víctimas, de carácter asistencial, evitando y previniendo nuevas agresiones, pero sin olvidar tampoco su carácter represivo, condenando gravemente a su agresor (CUNHAS; PINTO, 2008, traducción nuestra).

\subsection{Las Medidas de Asistencia a la Mujer Víctima de Violencia Doméstica o Fa- miliar}

El Estado Brasileño ocupa, lamentablemente, un lugar destacado, a nivel mundial, en el número de mujeres que sufren, o que han sufrido violencia de género. Datos de la Organización de las Naciones Unidas (ONU) indican que Brasil está en 70 (séptimo) lugar entre los países con el mayor índice de violencia contra la mujer -- mujeres entre 15 a 44 ańos --, estando únicamente por delante El Salvador, Trinidad y Tobago, Guatemala, Rúsia, Colombia y Belize (WAISELFISZ, 2012, traducción nuestra). De ahí la importancia de la actuación Estatal en aplicar y hacer cumplir las medidas preventivas y asistenciales de la Ley 11.340/2006.

En su artículo $6^{\circ}$, la Ley considera que la violencia doméstica y familiar como una de las formas de violación de los derechos humanos. Este notable reconocimiento tiene, según DIAS (2008, traducción nuestra), un carácter pedagógico. Además del carácter pedagógico de la Ley, también cabe destacar su carácter punitivo -- condenando el agresor --; y, su carácter asistencial, que puede ser visto desde el triple aspecto: social, salud y seguridad, y principalmente el carácter preventivo de la Ley, con la intención de cohibir 
y prevenir las agresiones contra las mujeres, garantizando su seguridad, de manera que puedan sobrevivir con total libertad, lejos de su agresor y, a ser posible, que no tengan que depender, bajo ningún concepto, de su agresor.

Por razones sistemáticas --y de espacio-- y también con la intención de hacer un estudio paralelo en la protección a la mujer trabajadora espańola y a la mujer trabajadora brasileña que sufre violencia de género -- LPIVG - o a la brasileña que es víctima de violencia doméstica y familiar -- Ley 11.340/2006 --, entre todos los aspectos relevantes e importantes de la Ley 11.340/2006 se realizarán algunas consideraciones al respecto de las medidas asistenciales, más precisamente, en lo que se refiere a la asistencia de la mujer trabajadora en el ámbito privado, prevista en el artículo $9^{\circ}$, párrafo $2^{\circ}$, inciso II de la Ley: [...] art. $9^{\circ}$ - La asistencia hecha a la mujer víctima de violencia doméstica y familiar será prestada en la forma articulada de conformidad con los principios y directrices previstas en la Ley Orgánica de la Asistencia Social (LOAS), en el Sistema Único de Salud (SUS) y en el Sistema Único de Seguridad Pública, entre otras normas y políticas públicas de protección y de emergencia cuando sea el caso. Además el párrafo $2^{\circ}$ establece que: [...] $\$ 2^{\circ}$ - El juez deberá garantizar a las mujeres en situaciones de violencia doméstica, para preservar su integridad física y psicológica: [...] II - el mantenimiento de la relación laboral, cuando sea necesario para la trabajadora ausentarse del trabajo por un plazo máximo de seis meses [...] (BRASIL, Ley 11.340/06, traducción nuestra).

La Ley trata de garantizar a la mujer que ha sufrido violencia doméstica y familiar la continuidad en su contrato de trabajo, hasta 6 (seis) meses, siendo competencia judicial la decisión de liberar a la mujer de comparecer en el trabajo durante ese tiempo. La ausencia en el trabajo de la mujer, en estos casos, será concedida para proteger su vida, integridad física y psicológica.

La medida de asistencia a la mujer generó derechos en el ámbito laboral, pues como se ha dicho, la ley concede el derecho a la mujer a ausentarse de su trabajo, sin que, en cambio, pierda su puesto de trabajo o vea su contrato rescindido debido a sus faltas.

Es sabido que una mujer con problemas familiares y que sufre constantes agresiones (físicas, morales o psicológicas) muchas veces se siente incapaz de acudir a su trabajo. Por eso, la aplicación de la medida prevista en el art. $9^{\circ}, \$ 2^{\circ}$, II se revela una de las acciones fundamentales para la mujer víctima, una vez que, sobre todo en este momento, la mujer necesita proveer su propio sustento y, para tanto, ella precisa seguir trabajando. Por eso, la medida contenida en la Ley, al asegurar el mantenimiento del vínculo laboral de la víctima, que trabaja en el servicio público (Art. $9^{\circ}, \$ 2^{\circ}$, I) o en la iniciativa privada (Art. $9^{\circ}$, $\$ 2^{\circ}$, II) debe ser valorada positivamente (DIAS, 2008, traducción nuestra).

Cabe destacar también que la conservación del puesto de trabajo, está prevista en el artículo $3^{\circ}$ de la Ley 11.340/2006, cuando establece que a todas las mujeres víctimas 
de violencia doméstica y familiar les serán aseguradas condiciones para el ejercicio del efectivo derecho a vida, a la seguridad, alimentación, educación, cultura, morada, acceso a la justicia, al deporte, al ocio, al trabajo, ciudadanía, libertad, dignidad y al respecto a la convivencia familiar y comunitaria (BRASIL, 11.340/2006, traducción nuestra).

A pesar de que el trabajo está asegurado en la Ley tanto en el art. $3^{\circ}$ como en el art. $9^{\circ}$, lo que es sin duda relevante e importante para la mujer, generando ciertas implicaciones en el ámbito del derecho laboral, lo cierto es que el legislador brasileño no dejó claro algunas situaciones posibles para hacer que la referida garantía sea verdaderamente eficaz.

Entre los puntos controvertidos en cuanto a la aplicación del referido artículo, podemos citar, de forma breve y resumida, tres cuestiones suscitadas desde la aprobación de la Ley y que hasta el momento no se conoce con certeza cuáles son las respuestas.

\subsection{Cuestiones Controvertidas Respecto del Artículo 9, $\$ 2^{\circ}$, II}

Son tres las cuestiones controvertidas y no aclaradas por la Ley 11.340/2006 con relación al derecho previsto en su artículo 9, párrafo 2º, inciso II: 1) Qué órgano judicial deberá determinar los casos en que la trabajadora podrá ausentarse de su trabajo; 2) Cuál es la naturaleza jurídica del tiempo en que la trabajadora necesita ausentarse de su trabajo, como medida de protección; y 3) Durante el plazo de seis meses en que la trabajadora puede ausentarse de su trabajo por resolución judicial ¿̨tendrá alguna ayuda financiera?

\section{Competencia del juez para decidir al respecto de la medida protectora del Art. $9^{\circ}, \$ 2^{\circ}, I$}

Conforme a la redacción del Art. 9o, $\$ 2^{\circ}$, II, de la Ley “Maria da Penha”, el juez asegurará a la mujer en situación de violencia doméstica y familiar -- como medida de protección de su integridad física o psíquica -- el mantenimiento de su vínculo laboral, cuando fuera necesario el alejamiento de su centro de trabajo, hasta por 6 (seis) meses. El primer problema que se verifica a partir de la simple lectura del artículo, es saber: ¿qué juez es el competente por decidir esta medida, cuando concurran los requisitos que autorizan su concesión?

Como la Ley no especifica cuál es el órgano competente para juzgar y aplicar la referida medida, resta saber, por lo tanto, si la competencia lo tiene la justicia común (civil o penal) o especial (laboral o especializado en violencia doméstica y familiar).

Para Maria Berenice Dias, la competencia para decidir respecto del mantenimiento del vínculo laboral será del JVDFM - "Juizados de Violência Doméstica e Familiar contra a Mulher" ${ }^{1}$ - y, mientras no sean creados, la tarea es del juez de lo penal o, del juez de lo

1 JVDFM: Juzgados de Violencia Domestica y Familiar contra la mujer (traducción nuestra). 
civil ("Vara da Família"), dependiendo de cuál sea el suplico de la víctima (DIAS, 2008, traducción nuestra).

En oposición a la referida autora, el jurista Sérgio Pinto Martins entiende que la competencia para juzgar en estos casos será de la Justicia del Trabajo, por tratarse de una cuestión propia de la relación laboral -- alejamiento del puesto de trabajo -- y también por fuerza del inciso I del artículo 114 de la Constitución Federal (Compete à Justiça do Trabalho processar e julgar: I as açóes oriundas da relação de trabalho, abrangidos os entes de direito público externo e da administração pública direta e indireta da União, dos Estados, do Distrito Federal e dos Municípios)².

Parece más acertado el segundo posicionamiento, pues una vez que se han confirmado los requisitos del art. $9^{\circ}, \$ 2^{\circ}$, II, que autorizan el alejamiento de la trabajadora hasta 6 (seis) meses de su trabajo, para el mantenimiento de su vínculo laboral, deberá ser solicitado al juez laboral, una vez que es el órgano competente para decidir sobre los aspectos del contrato de trabajo presentes en la relación laboral. Resáltese que la competencia del juez laboral se confirma, sobre todo en los casos en que deberá ser analizado si hay o no una relación de trabajo entre la víctima y su empleador, cuando, por ejemplo, se trate de un trabajo de economía sumergida.

La prerrogativa de la Justicia Laboral, prevista en el artículo 114, I de la CRFB/88, es absoluta, por tratarse de competencia en razón de la materia. Lo que implica decir que, aunque se refiera a una medida protectora prevista en legislación especial, la competencia para juzgar conflictos de orden laboral, que se pronuncian respecto a la relación laboral entre trabajador y empresario es de la Justicia Laboral, aunque el empleador en nada contribuyó para que su trabajadora tuviera que ausentarse de su puesto de trabajo.

\section{Naturaleza jurídica del tiempo en que la trabajadora necesita ausentarse de su trabajo, como medida de protección}

Analizando las repercusiones del art. 9, $\$ 2^{\circ}$, II, de la Ley 11.340/2006 en el derecho laboral, cabe destacar el esfuerzo de la doctrina en explicar la naturaleza jurídica del período (hasta seis meses) en que la trabajadora puede ausentarse de su puesto de trabajo para salvaguardar su derecho a la vida y su integridad física y psíquica, asegurando el mantenimiento de su puesto de trabajo durante el referido período (hasta seis meses).

El período en que no hay prestación laboral por parte de la trabajadora, ante la imposibilidad de comparecer al trabajo, para la legislación laboral, puede considerarse como interrupción o suspensión del contrato de trabajo.

2 Corresponde a la Justicia Laboral procesar y juzgar: I-las acciones derivadas de la relación de empleo, tanto de derecho público (Administración pública directa o indirecta de la Unión, Estados, del Distrito Federal y Municipios) como de derecho privado (BRASIL, CRFB/88, ART. 114, I, traducción nuestra). 
La doctrina brasileña, según Vólia Bomfim Cassar, se encargó de adoptar una terminología propia (suspensión e interrupción) para denominar los períodos de paralización de una o algunas cláusulas contractuales, abandonando los criterios de la doctrina extranjera, que subdivide la suspensión en total -- verdadera suspensión -- y parcial -- interrupción -- (CASSAR, 2014, traducción nuestra).

De manera muy clara, la diferencia entre interrupción y suspensión del contrato de trabajo, para Maurício Godinho Delgado, es la siguiente: en la suspensión, la cesación del contrato de trabajo es total, no hay abono de sueldos y el período de alejamiento del puesto de trabajo no se computa como período de tiempo de servicio efectivo. En la interrupción cesa el contrato de trabajo parcialmente, pero hay pago de la remuneración debida y el período de alejamiento cuenta como tiempo de servicio (DELGADO, 2014, traducción nuestra).

Alice Montero de Barros, en el mismo sentido, esclarece que en ciertos casos no existe prestación de servicio por parte del trabajador e igualmente, el empleador paga su sueldo, tratándose de un caso típico de interrupción contractual. Por el contrario, en la suspensión del contrato de trabajo aunque también existir la cesación temporal de la prestación del servicio, no hay abono de salarios y tampoco el período de alejamiento será considerado a efectos legales (BARROS, 2009, traducción nuestra).

Para que fuese un caso de interrupción del contrato de trabajo -- con percepción de sueldo--, el período en que la trabajadora permaneciese ausente en el trabajo, la Ley 11.340/2006 debería imponer la obligación al empleador de forma expresa, ya que, según el principio de la legalidad, nadie está obligado a hacer o dejar de hacer alguna cosa excepto por mandato de la ley (BRASIL, CRFB/88, art. 5, II, traducción nuestra).

El autor brasileńo, Sergio Pinto Martins, defiende que durante el tiempo en que la trabajadora permanece ausente del trabajo, el contrato de trabajo se suspenderá y todos los efectos de la relación jurídica de trabajo también se suspenden, o sea, no hay prestación laboral, pero tampoco hay abono del sueldo o cómputo de este tiempo como tiempo de servicio para cualquier fin.

No obstante, encuadrándose el alejamiento previsto en el artículo $9^{\circ}, \$ 2^{\circ}$, inciso II, de la Ley 11.340/2006 como suspensión del contrato de trabajo, la falta de remuneración durante este período - ya que el empleador no está obligado por la Ley a pagar el sueldo a la trabajadora durante su ausencia - podría impedir a la mujer intentar alejarse de su agresor en virtud de su dependencia financiera, lo que tornaría la medida en totalmente ineficaz.

Está claro que el período en que la mujer tiene una resolución judicial de alejamiento de su agresor y de su trabajo, es el momento en que la mujer víctima necesita buscar su independencia, sobre todo la independencia financiera. Por lo tanto, la solución más 
adecuada es la suspensión del contrato de trabajo, manteniéndose el vínculo laboral de la mujer, no obstante no tendrá derecho a recibir sueldo de su empleador, pero sí de la Seguridad Social, al igual que ocurre con las prestaciones debidas a la mujer en licencia por el embarazo (BRASIL, CLT, Art. 392) o cuando el trabajador tiene que ausentarse del trabajo por motivo de enfermedad o accidente (Cunha e Pinto, 2009, traducción nuestra).

\section{Proyecto de ley no 296/2013 del Senado federal que trata del beneficio de "au- xílio-transitório" para mujeres que sufren violencia doméstica o familiar}

En 2016 hará 10 años que la "Lei Maria da Penha" fue promulgada y pasó a ser un verdadero instrumento de combate frente a la violencia doméstica y familiar en el Estado Brasileño. No obstante, todavía hace falta una normativa que venga a ofrecer una verdadera asistencia a la mujer víctima del maltrato.

Como ya se ha señalado anteriormente, tal obligación no puede recaer sobre el empleador de la víctima, principalmente por dos motivos: 1) la mujer víctima tiene que ausentarse de su trabajo por motivos ajenos a su voluntad, de la misma manera que el empleador no ha generado la referida ausencia, tampoco tiene, por lo tanto, el deber de remunerar a la trabajadora durante el período en que esté ausente de su trabajo; 2) si tal cargo recayera sobre el empleador, muy probablemente generaría una discriminación a la contratación de féminas en el mercado de trabajo, ya que los empleadores tendrían conciencia de que durante la vigencia del contrato de trabajo, la mujer podría utilizar la medida protectora y sin recibir la prestación laboral, tendría que pagar los emolumentos.

La medida protectora de alejamiento no va en contra la protección del mercado laboral de la mujer (BRASIL, CRFB/88, Art. $7^{\circ}, \mathrm{XX}$ ), una vez que durante este período el empleador no tiene que cubrir cualquier obligación a su cuenta.

No obstante, si el objetivo de la Ley es proteger a la mujer de la violencia doméstica y familiar, para que pueda disponer de sus derechos y pueda vivir con dignidad, también deberá ser objeto de la Ley establecer mecanismos que le garanticen su subsistencia, ya que dejarla sin amparo en este momento supone una infracción del principio de la dignidad de la persona humana (BRASIL, CRFB/88, Art. 1, II) y una quiebra del Estado Democrático de Derecho Brasileńo que debe preservar la salud de todos sus ciudadanos (BRASIL, CRFB/88, Art. 194).

Siguiendo el ejemplo de legislaciones más avanzadas sobre el tema, como es el caso de la legislación española --tratada anteriormente en este artículo --, donde se reconoce la existencia del riesgo social y de la protección que las mujeres necesitan de esta atención por parte del Estado, y ofrece una prestación de la Seguridad Social a la mujer víctima de la violencia de género para proveer su sustento y el de sus hijos, lejos de su agresor, durante el tiempo en que la mujer no puede acudir a su trabajo, norma que a nuestro juicio es muy acertada. 
Desde el año de 2013 está en trámite en el Senado Federal Brasileño, un proyecto de ley (PL286/2013) que modifica la Ley de la Seguridad Social Brasileńa (BRASIL, Lei $8.213 / 91$ ) y la propia Ley 11.340/2006, reconociendo el riesgo social afrontado por la mujer trabajadora -- víctima de violencia doméstica y familiar -- y ofrece una prestación (remuneración) que deberá ser pagado por el INSS (Estado) durante el tiempo en que la trabajadora tenga necesidad de ausentarse de su puesto de trabajo para protegerse.

La prestación de la Seguridad Social, que está en trámite, tiene el nombre de "auxílio-transitório" y será abonado a las mujeres víctimas de violencia doméstica y familiar que tengan que ausentarse de su trabajo. Según el proyecto, la prestación seguirá los mismos moldes de la prestación ofrecida a los trabajadores víctimas de accidente de trabajo.

La inclusión de la violencia doméstica y familiar como un riesgo social afrontado por las mujeres brasileńas y el ofrecimiento de la correspondiente prestación asistencial a la víctima no puede ser vista como si se tratase de una ayuda por parte del Estado, más sí de una obligación, de un deber del Estado...como si se trata de una ayuda por parte del Estado, más si una obligación, un deber del Estado en garantizar el efectivo ejercicio de la ciudadanía, de la observancia del principio de la dignidad de la persona humana y sobre todo de posibilitar, sin discriminación, la justicia y paz social.

Lo que se espera es que un Proyecto de Ley de gran importancia, como éste que está en trámite en el Senado, sea aprobado, a pesar de encontrarse en estos momentos en una situación de inestabilidad económica-financiera.

\section{Conclusión}

La protección a la mujer que sufre violencia de género -- España -- y a la mujer que sufre violencia doméstica y familiar -- Brasil -- tiene un enfoque multidisciplinar per con reflejo directo en el contrato de trabajo de la mujer víctima.

Las Leyes han tenido como años de su publicación dos momentos muy cercanos, la LPIVG en el año 2004 y la Ley "Maria da Penha" en el año de 2006. En lo que respecta a las repercusiones sobre los derechos de las mujeres previstos en estos dos sistemas jurídicos, la legislación española está más adelantada en la interpretación y en la aplicabilidad de las medidas en comparación con el ordenamiento brasileño.

Está claro que aún quedan por solventar algunas lagunas existentes en la Ley española, pero ya se ha recorrido una gran parte del camino. En el caso brasileño, la gran necesidad de las mujeres en tener una legislación especializada para cohibir, prevenir y punir a sus agresores, ha priorizado y extendido la aplicación de las medidas de urgencia, - como el alejamiento del agresor a su víctima - y ha dejado en segundo plano la medida asistencial prevista en el artículo $9^{\circ}$, párrafo $2^{\circ}$, inciso II de la Ley "Maria da Penha”, que garantiza el mantenimiento del vínculo de empleo por hasta seis meses. 
El ordenamiento español además de estar más adelantado en ofrecer medidas de asistencia integral a las mujeres víctimas de violencia, también podrá servir de ejemplo para la implementación de algunas alteraciones y/o mejoras en la Ley brasileña.

Lo que no deja lugar a dudas es que, tanto en el ordenamiento espańol, como en el brasileño las mujeres víctimas de violencia son merecedoras de una asistencia integral por parte del Estado, tendente a garantizar a las mujeres una vida digna, segura y libre de cualquier tipo de violencia machista.

\section{Referências}

ALBERDI, I. y MATAS, N.: La violencia doméstica. Informe sobre los malos tratos a mujeres en España, Barcelona (Fundación La Caixa), 2002.

ARAMEDI SANCHEZ, P.: "Los aspectos laborales de la Ley de medidas de protección integral contra la violencia de género", Revista de Derecho Social, núm. 30, 2005.

BLASCO JOVER, C.: "La protección de la trabajadora víctima de maltrato en la LO $1 / 2004$, de 28 de diciembre, de medidas de protección integral contra la violencia de género", Relaciones Laborales, núm, 21, 2005.

BARROS, A. M. de. Curso de direito do trabalho. São Paulo: LTr, 2009.

BRASIL, Constituição da República Federativa do, 1988. CRFB/88.

BRASIL, Consolidação das Leis Trabalhistas, 1943. CLT/4.

BRASIL, Lei 8.213/91.

BRASIL, Lei 11.340/2006.

CAMPOS, A. H.; CORRÊA, L. R. Direitos Humanos das Mulheres. 1. ed. Curitiba: Juruá, 2011.

CASSAR, V. B. Direito do trabalho. 9 ed. São Paulo: MÉTODO, 2014.

CAVAlCANTI, S. V. S. de F. Violência doméstica: análise da Lei "Maria da Penha" no 11.340/06. 3a ed. rev. ampl. Salvador: Editora Juspodivum, 2010.

CAVAS MARTINEZ, F.: "La protección jurídico-laboral de las mujeres víctimas de violencia de género", en VV.AA (SANCHEZ TRIGUEROS, C., Coord.): La presencia femenina en el mundo laboral: metas y realidades, Pamplona (Aranzadi), 2006.

CEINOS SUAREZ, A.: El desistimiento como causa de extinción del contrato de trabajo, Pamplona (Aranzadi), 2008.

CUNHA, R. S.; PINTO, R. B. Violência Doméstica: Lei Maria da Penha (Lei 11.340/2006)

Comentado artigo por artigo. 2. ed. São Paulo: Revista dos Tribunais, 2008. 
DE LA PUEBLA PINILLA, A.: “Aspectos laborales y de protección social en la Ley Orgánica 1/2004, de 28 de diciembre, de medidas de protección integral contra la violencia de género", Relaciones Laborales, núm. 6, 2005.

DELGADO, M. G. Curso de direito do trabalho. 13 ed. São Paulo: LTr, 2014.

DIAS, M. B. A Lei Maria da Penha na justiça: A efetividade da Lei 11.340/2006 de combate à violência doméstica e familiar contra a mulher. São Paulo: Revista dos Tribunais, 2008.

DIAS, M. B. Uma lei com nome de mulher, 2012. Disponíble em <http://mariaberenice. com.br/uploads/uma_lei_com_nome_de_mulher.pdf>. 20 marzo 2015.

FARALDO CABANA, C.: "El derecho de las trabajadoras víctimas de violencia de género al cambio de lugar de trabajo y a la movilidad geográfica”, Revista Española de Derecho del Trabajo, núm. 153, 2012.

FARALDO CABANA, C.: "La pérdida de la condición de beneficiario de la pensión de viudedad del condenado por homicidio o lesiones en el contexto de la violencia doméstica y de género", Relaciones Laborales, núm. 13-14, 2012.

FERNANDEZ LOPEZ, M.F.: La dimensión laboral de la violencia de género, Albacete (Bomarzo), 2005.

FERRADANS CARAMES, C.: "Medidas laborales de la Ley de protección contra la violencia de género y negociación colectiva”, Revista de Derecho Social, núm. 32, 2005.

GALA DURAN, C.: "Violencia de género y Derecho del Trabajo: una aproximación a las diversas medidas previstas", Relaciones Laborales, núm. 10, 2005.

GARCIA NINET, J.I.: "Medidas laborales previstas en la Ley Orgánica 1/2004, de 28 de diciembre, de medidas de protección integral contra la violencia de género (II)”, Tribuna Social, núm. 170, 2005.

IBGE - Instituto Brasileiro 2010 Disponíble en http://noticias.r7.com/brasil/noticias/ pesquisa-ibge-68-das-mulheres-agredidas-sao-vitimas-de-companheiros-20100917. html Aceso en 14/05/2015.

KAHALE CARRILLO, D.T.: "El reconocimiento de los derechos laborales a las mujeres víctimas de violencia de género en los convenios colectivos”, Aranzadi Social, 2007.

LANDA ZAPIRAIN, J.P.: "Aspectos problemáticos de las medidas de protección social previstas en favor de las mujeres objeto de situaciones de violencia de género por la LO 1/2004, de 28 de diciembre", Tribuna Social, núm. 56, 2007.

LOUSADA AROCHENA, J.F.: “Aspectos laborales y de Seguridad Social de la violencia de género en la relación de pareja", Actualidad Laboral, núm. 7, 2005. 
MARTIN PUEBLA, E.: "Medidas laborales de protección contra la violencia de género", Tribuna Social, núm. 179, 2005.

MARTINS, S. P. Direito do Trabalho. São Paulo: Atlas, 2013.

MATEU CARRUANA, M.J.: Medidas laborales, de protección social y de fomento del empleo para las victimas de violencia de género, Madrid (Dykinson), 2007.

MELlO, A. R. de. A Lei Maria da Penha e os Juizados de Violência Doméstica e Familiar contra a Mulher, p. 11. Disponível em: <http://www.stj.jus.br/publicacaoinstitucional/index.php/boletimdaenfam/article/viewFile/1618/1612> Acesso em $13 / 05 / 2015$.

MENENDEZ SEBASTIAN, P. y VELASCO PORTERO, T.: La incidencia de la violencia de género en el contrato de trabajo, Madrid (Cinca), 2006.

MOLINA NAVARRETE, C.: “Las dimensiones socio-laborales de la `lucha’ contra la violencia de género. A propósito de la LO 1/2004, de 28 de diciembre, de medidas de protección integral contra la violencia de género --BOE de 29 de diciembre--", Revista Trabajo y Seguridad Social (Centro Estudios Financieros), núm. 264, 2005.

ONU. Estudio a fonto sobre todas las formas de violência contra la mujer, 2006. Disponíble en: <http://www.cepal.org/mujer/noticias/paginas/1/27401/InformeSecreGeneral.pdf> 14 maio 2015 .

QUINTANILLA NAVARRO, B.: "Violencia de género y derechos sociolaborales: la L.O $1 / 2004$, de 28 de diciembre, de medidas de protección integral contra la violencia de género", Temas Laborales, núm. 80, 2005.

QUIROS HIDALGO, J.G.: "La dimisión sui generis de la trabajadora víctima de violencia de género", Actualidad Laboral, núm. 11, 2008.

RODRIGUEZ ESCANCIANO, S.: La protección jurídico laboral de la mujer: luces y sombras, Barcelona (Cedecs), 2002.

RODRIGUEZ ESCANCIANO, S.: Los permisos parentales: avances y retrocesos tras las últimas reformas, Albacete (Bomarzo), 2013.

SELMA PENALVA, A.: "Incidencia de la violencia de género sobre las normas laborales", Actualidad Laboral, núm. 9, 2011, pág. 1056.

SEMPERE NAVARRO, A.V. y BARRIOS BAUDOR, G.L.: "Relaciones laboral y funcionarial”, en VV.AA (RIVAS VALLEJO, M.P. y BARRIOS BAUDOR, G.L., Dirs.): Violencia de género. Perspectiva multidisciplinar y práctica forense, Pamplona (Aranzadi), 2006.

SEMPERE NAVARRO, A.V.: "Aspectos sociolaborales de la LO 1/2004, de 28 de diciembre”, en VV.AA (MUERZA ESPARZA, J., Coord.): Comentario a la Ley Orgánica de Protección Integral contra la Violencia de Género, Pamplona (Aranzadi), 2005. 
SOUZA, S. R. Comentários à lei de combate à violência contra a mulher. $2^{\mathrm{a} e d}$. Curitiba: Juruá, 2008.

VILA TIERNO, F.: "Medidas de mantenimiento del empleo para las trabajadoras víctimas de violencia de género", en VV.AA (QUESADA SEGURA, R., Dir.): Perspectiva laboral de la protección contra la violencia de género, Granada (Comares), 2009.

WAISELFISZ, Julio Jacobo. Mapa da violência 2012: Caderno Complementar 1: Homicídio de Mulheres no Brasil. São Paulo, Instituto Sangari, 2012, p. 11. Disponível em: <http://www.mapadaviolencia.org.br/pdf2012/mapa2012_mulher.pdf>. 14 maio 2015. 